\title{
Synthesis and Fluorescence Properties of Europium-Substituted Lanthanum Orthophosphate and Condensed Phosphates
}

\author{
Hiroaki Onoda, Takehiro Funamoto \\ Department of Informatics and Environmental Sciences, Kyoto Prefectural University, \\ Kyoto, Japan \\ Email: onoda@kpu.ac.jp
}

Received October 18, 2011; revised December 9, 2011; accepted January 22, 2012

\begin{abstract}
Mixtures of lanthanum oxide, europium oxide, and phosphoric acid were heated with various ratios of $\mathrm{P} /(\mathrm{La}+\mathrm{Eu})$ and $\mathrm{Eu} /(\mathrm{La}+\mathrm{Eu})$. The obtained phosphates were estimated using XRD patterns, FT-IR spectra, and SEM images. The fluorescence spectra and resistance against hydrofluoric acid were estimated as functional properties of these phosphate materials. The condensed phosphates showed a strong peak at $615 \mathrm{~nm}$ and high resistance against hydrofluoric acid.
\end{abstract}

Keywords: Condensed Phosphate; Europium; Fluorescence; Resistance against Hydrofluoric Acid

\section{Introduction}

Phosphates are transformed to other forms of phosphates by hydrolysis and dehydration reactions at elevated temperatures $[1,2]$. Polyphosphate and ultraphosphate are included in a group of condensed phosphates. Polyphosphate has a chain structure in which the $\mathrm{PO}_{4}$ unit shares two oxygen atoms and ultraphosphate has a network structure. Formation of these condensed phosphates was affected by the ratio of phosphorus/cation, heating temperature, time, atmosphere, and so on [3-5]. Therefore, it was difficult to obtain a high yield of the condensed phosphates. Consequently, orthophosphate has been investigated for various uses, but condensed phosphates have been little studied. Orthophosphate materials have been used for ceramic materials, catalysts, fluorescent materials, dielectric substances, metal surface treatment, detergent, food additives, fuel cells, pigments, etc. $[6,7]$. The condensed phosphates have different properties from those of orthophosphates and can therefore be used as novel functional materials [8-10].

Rare-earth phosphates have a high melting point and large specific surface area in phosphate materials $[11,12]$. Rare-earth orthophosphates, which are the main component of rare-earth ores, are stable phosphate groups in acidic and basic solutions. Their resistance in acidic and basic solutions was developed into other phosphate materials [13]. Moreover, rare earth elements are important in fluorescence properties. Especially, the addition of europium indicated strong fluorescence in materials of various kinds [14].

Metals, oxides, and silicates are useful materials, but they are vulnerable to the effects of hydrofluoric acid, which is a reagent used in many industrial applications. However, its wastes are not easily disposed of [15]. Furthermore, throughout Africa, China, the Middle East, and southern Asia (India and Sri Lanka), groundwater contains a certain amount of hydrofluoric acid. Therefore, for materials used with such polluted water from plants and at the developing area, resistance against hydrofluoric acid is important [16]. Because phosphate materials have a certain degree of resistance against hydrofluoric acid, these materials can be used with hydrofluoric acid. Nevertheless, the extent of that resistance remains unclear.

For this study, the europium-substituted lanthanum condensed phosphates were synthesized from lanthanum oxide, europium oxides, and phosphoric acid. The respective chemical compositions and particle shapes of the obtained products were evaluated. Furthermore, these phosphate materials were studied for their fluorescence properties and resistance in hydrofluoric acid.

\section{Experimental}

Lanthanum oxide $\left(\mathrm{La}_{2} \mathrm{O}_{3}\right)$ was mixed with $85 \mathrm{wt} \%$ phosphoric acid $\left(\mathrm{H}_{3} \mathrm{PO}_{4}\right)$ at mole ratios of $\mathrm{P} / \mathrm{La}=1,2,3$, 4 , and 5 . The $0.5,1,2,3$, and $4 \mathrm{~mol} \%$ of lanthanum oxide was substituted with europium oxide $\left(\mathrm{Eu}_{2} \mathrm{O}_{3}\right)$. These mixtures were heated at $700^{\circ} \mathrm{C}$ for $20 \mathrm{hr}$ under air con- 
ditions.

The respective chemical compositions of these thermal products were analyzed using X-ray diffraction (XRD) and Fourier transform infrared spectroscopy (FT-IR). $\mathrm{X}$-ray diffraction patterns were recorded on a Rigaku Denki RINT2000 X-Ray diffractometer using monochromated $\mathrm{CuK} \alpha$ radiation. The IR spectra were recorded (FT-IR 720; Horiba Ltd.) using a $\mathrm{KBr}$ disk method. The particle shapes of phosphate powder were observed from scanning electron micrographs (SEM, JGM-5510LV; JEOL).

The fluorescence properties were measured using a luminescence spectrometer (LS55; Perkin-Elmer). The resistance of materials against hydrofluoric acid was estimated using the following method. The $0.2 \mathrm{~g}$ of thermal products was allowed to stand in $100 \mathrm{ml}$ of $5 \mathrm{wt} \%$ of hydrofluoric acid for 1 day. Then, a solid was removed by filtration. The residual ratio was calculated with the dried solid.

\section{Results and Discussion}

\subsection{Chemical Compositions and Particle Shapes of Europium-Substituted Lanthanum Condensed Fhosphates}

The europium-substituted lanthanum phosphates showed the same XRD patterns as those with lanthanum phosphates without the substitution because the ratio of europium was sufficiently small. Figure 1 shows XRD patterns of samples prepared with various $\mathrm{P} / \mathrm{La}$ ratios. Peaks of lanthanum orthophosphate, polyphosphate, and ultraphosphate were observed in XRD patterns of samples prepared respectively with $\mathrm{P} / \mathrm{La}=1,3$, and 5 . These compounds were formed in the following reactions.

$$
\begin{aligned}
& \mathrm{La}_{2} \mathrm{O}_{3}+2 \mathrm{H}_{3} \mathrm{PO}_{4} \rightarrow 2 \mathrm{LaPO}_{4}+3 \mathrm{H}_{2} \mathrm{O} \\
& \mathrm{La}_{2} \mathrm{O}_{3}+6 \mathrm{H}_{3} \mathrm{PO}_{4} \rightarrow 2 \mathrm{La}\left(\mathrm{PO}_{3}\right)_{3}+9 \mathrm{H}_{2} \mathrm{O} \\
& \mathrm{La}_{2} \mathrm{O}_{3}+10 \mathrm{H}_{3} \mathrm{PO}_{4} \rightarrow 2 \mathrm{LaP}_{5} \mathrm{O}_{14}+15 \mathrm{H}_{2} \mathrm{O}
\end{aligned}
$$

Samples prepared with $\mathrm{P} / \mathrm{La}=2$ and 4 were, respecttively, mixtures of lanthanum orthophosphate-polyphosphate, and polyphosphate-ultraphosphate. The chemical composition was closely related with the $\mathrm{P} / \mathrm{La}$ ratio.

Figure 2 portrays IR spectra of samples prepared with various $\mathrm{P} / \mathrm{La}$ ratios. Samples with substitution by europium also had the same IR spectra as those of samples without the substitution. The small absorption peak at $1630 \mathrm{~cm}^{-1}$ in the spectrum of the sample prepared with $\mathrm{P} / \mathrm{La}=1$ was attributable to the adsorbed water after thermal synthesis. The sample prepared with $\mathrm{P} / \mathrm{La}=1$ had a much different spectrum from those of other samples. The most important peak at $770 \mathrm{~cm}^{-1}$ was from $\mathrm{P}-\mathrm{O}-\mathrm{P}$ bonding in condensed phosphates [17]. Samples prepared with $\mathrm{P} / \mathrm{La}=2$ had the middle spectrum between samples prepared with $\mathrm{P} / \mathrm{La}=1$ and 3. Additionally, the

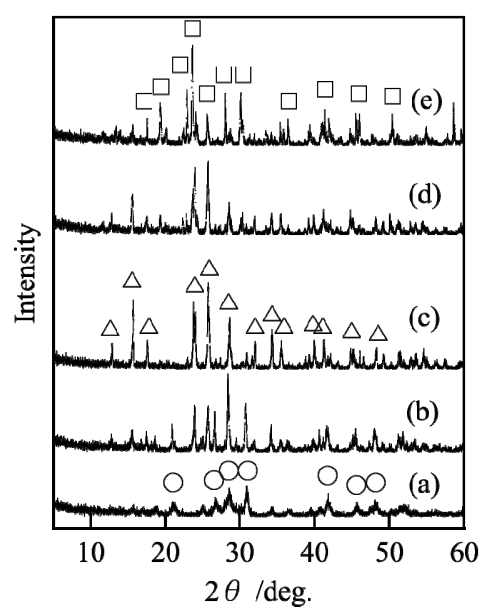

Figure 1. XRD patterns of samples prepared with various $\mathrm{P} / \mathrm{La}$ ratios: (a) $\mathrm{P} / \mathrm{La}=1$; (b) 2 ; (c) 3 ; (d) 4 ; and (e) 5 ; $\circ$ :

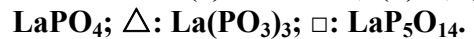

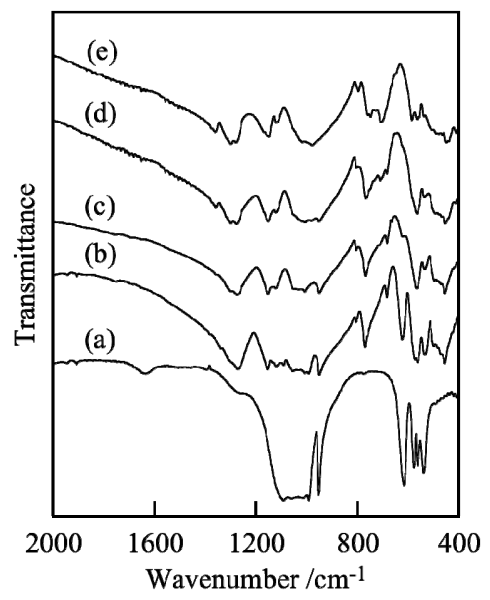

Figure 2. IR spectra of samples prepared with various $\mathrm{P} / \mathrm{La}$ ratios: (a) $\mathrm{P} / \mathrm{La}=1$; (b) 2; (c) 3; (d) 4; and (e) 5 .

sample prepared with $\mathrm{P} / \mathrm{La}=4$ was intermediate between samples prepared with $\mathrm{P} / \mathrm{La}=3$ and 5 . These results corresponded with those obtained using XRD analyses.

Figure 3 depicts SEM images of samples prepared with various $\mathrm{P} / \mathrm{La}$ ratios. Samples prepared with $\mathrm{P} / \mathrm{La}=1$ had small particles. The particle size became larger from $1-3$ to $15-20 \mu \mathrm{m}$ with the increase of the $\mathrm{P} / \mathrm{La}$ ratio. The particles had a plane at samples prepared with $\mathrm{P} / \mathrm{La}$ $=3,4$, and 5 . After substitution with europium, no change was observed in the particle size or shape.

\subsection{Functional Properties of Phosphate Materials}

The excitation spectra were measured for the fluorescence at $613 \mathrm{~nm}$ of the europium-substituted lanthanum phosphates [18]. Samples prepared with $\mathrm{P} /(\mathrm{La}+\mathrm{Eu})=1$ and 2 adsorbed at $250-260 \mathrm{~nm}$ of excitation. However, shorter wavelengths than $240 \mathrm{~nm}$ were suitable for sam- 

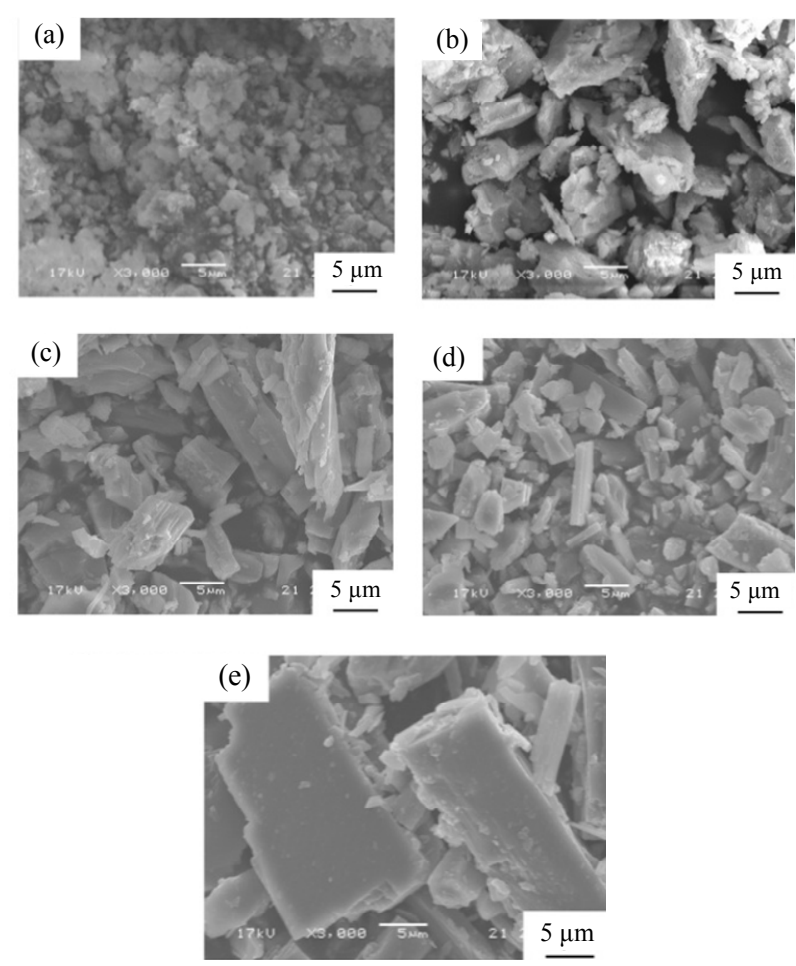

Figure 3. SEM images of samples prepared with various P/La ratios: (a) P/La $=1$; (b) 2; (c) 3; (d) 4; and (e) 5 .

ples prepared with $\mathrm{P} /(\mathrm{La}+\mathrm{Eu})=3$, 4, and 5. As inferred from the chemical composition, orthophosphate materials were excited by $250-260 \mathrm{~nm}$ of ultraviolet radiation. In subsequent measurements, $254 \mathrm{~nm}$ wavelength was used for comparison. Figure 4 shows the fluorescence peak intensity at $590 \mathrm{~nm}$ of samples prepared using various concentrations of europium (excitation, $254 \mathrm{~nm}$ ). The europium ratio showing the strongest peaks was varied from the $\mathrm{P} /(\mathrm{La}+\mathrm{Eu})$ ratio. A sample prepared with $\mathrm{P} /(\mathrm{La}$ $+\mathrm{Eu})=2$ indicated a strong peak at $4 \mathrm{~mol} \%$ of europium. However, samples prepared with $\mathrm{P} /(\mathrm{La}+\mathrm{Eu})=2$ had a strong peak at $0.5 \mathrm{~mol} \%$ of europium. These optimum concentrations of europium were unrelated with the $\mathrm{P} /(\mathrm{La}+$ $\mathrm{Eu})$ ratio. The peak intensity of all samples became small with the increase of the europium ratio to $5 \mathrm{~mol} \%$.

Figure 5 portrays the fluorescence spectra of samples prepared using various $\mathrm{P} /(\mathrm{La}+\mathrm{Eu})$ ratios (excitation, 254 $\mathrm{nm}$ ). These fluorescence spectra of all samples were selected at the optimum europium ratio. The peak intensity was weak for samples prepared with $\mathrm{P} /(\mathrm{La}+\mathrm{Eu})=3,4$, and 5 because the excitation wavelength was unsuitable in these measurements. Samples prepared with $\mathrm{P} / \mathrm{La}+$ $\mathrm{Eu})=3,4$, and 5 consisted of polyphosphate and ultraphosphate. These spectra show that the condensed phosphates had weaker peaks than those of orthophosphate. The fluorescent peaks at 556, 590, 615, 653, and $690 \mathrm{~nm}$ corresponded respectively to the transition from ${ }^{5} \mathrm{D}_{0}$ to ${ }^{7} \mathrm{~F}_{0},{ }^{7} \mathrm{~F}_{1},{ }^{7} \mathrm{~F}_{2},{ }^{7} \mathrm{~F}_{3}$, and ${ }^{7} \mathrm{~F}_{4}$. Some peaks were divided in

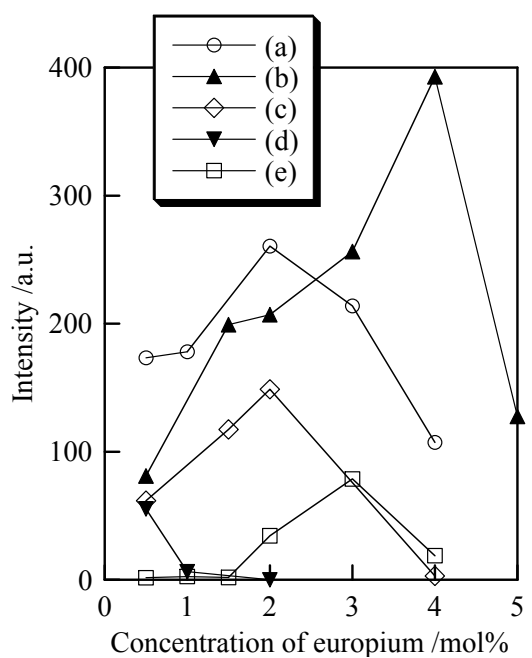

Figure 4. Fluorescence peak intensity at $590 \mathrm{~nm}$ of samples prepared using various concentrations of europium: (a) P/La $=1$; (b) 2; (c) 3; (d) 4; and (e) 5 .

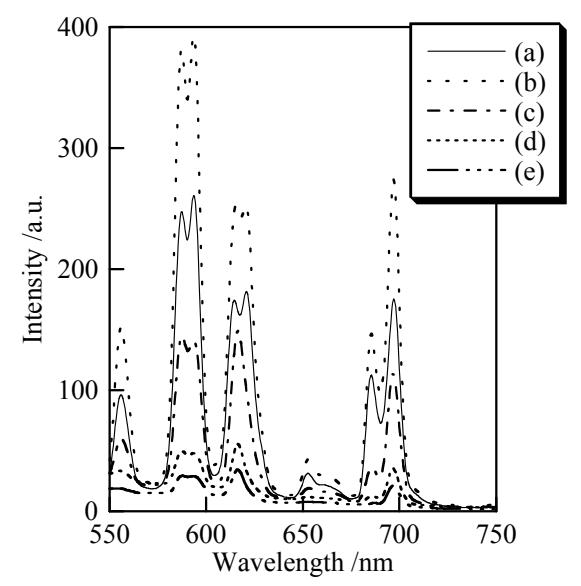

Figure 5. Emission spectra of samples prepared using various concentrations of europium: (a) $\mathrm{P} / \mathrm{La}=1$; (b) 2 ; (c) 3 ; (d) 4; and (e) 5 .

two because of the symmetry of phosphate structure. Figure 6 shows ${ }^{5} \mathrm{D}_{0} \rightarrow{ }^{7} \mathrm{~F}_{1} /{ }^{5} \mathrm{D}_{0} \rightarrow{ }^{7} \mathrm{~F}_{2}$ ratio of samples (excitation, $254 \mathrm{~nm})$. Samples prepared with $\mathrm{P} /(\mathrm{La}+\mathrm{Eu})=1$ and 2 showed a strong peak at $590 \mathrm{~nm}$. However, the peak at $615 \mathrm{~nm}$ was strong at samples prepared with $\mathrm{P} /(\mathrm{La}+\mathrm{Eu})=3,4$, and 5 . Ultraphosphate and polyphosphate were suitable for red luminescence.

Table 1 presents the residual ratios of samples from 5 $w t \%$ of hydrofluoric acid. A high residual ratio reflects high resistance against hydrofluoric acid. All samples showed residual ratios higher than $70 \%$. The condensed phosphates showed high resistance against hydrofluoric acid. Substitution with europium had little influence on these residual ratios. In the same conditions, silicon dioxide was dissolved completely to hydrofluoric acid. The phosphate materials showed much higher resistance against hydrofluoric acid. 


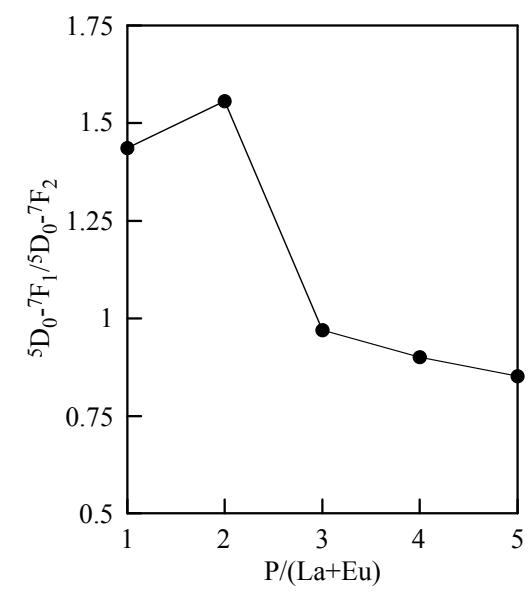

Figure 6. ${ }^{5} D_{0} \rightarrow{ }^{7} F_{1}{ }^{5} D_{0} \rightarrow{ }^{7} F_{2}$ ratios of samples.

Table 1. Residual ratio of samples from hydrofluoric acid (\%).

\begin{tabular}{ccc}
\hline \multirow{2}{*}{$\mathrm{P} /(\mathrm{La}+\mathrm{Eu})$} & \multicolumn{2}{c}{ Europium concentration $/ \mathrm{mol} \%$} \\
\cline { 2 - 3 } & 0 & 4 \\
\hline 1 & 71.5 & 74.6 \\
2 & 80.2 & 83.7 \\
3 & 83.1 & 79.3 \\
4 & 85.9 & 86.4 \\
5 & 86.9 & 84.9 \\
\hline
\end{tabular}

\section{Conclusion}

Europium-substituted lanthanum phosphates were synthesized from lanthanum oxide, europium oxide, and phosphoric acid. The europium ratio which showed the strongest fluorescence peaks varied according to the $\mathrm{P} /(\mathrm{La}+\mathrm{Eu})$ ratio. The peak intensity of all samples became small with the increase of the europium ratio to 5 mol\%. Lanthanum ultraphosphate and polyphosphate were more suitable materials than orthophosphate for red luminescence. These phosphate materials had a high residual ratio from hydrofluoric acid.

\section{REFERENCES}

[1] M. T. Averbuch-Pouchat and A. Durif, "Topics in Phosphate Chemistry," World Scientific Publishing Co. Pte. Ltd., Singapore, 1996.

[2] I. Hammas, K. Horchani-Naifer and M. Ferid, "Conduction properties of Condensed Lanthanum Phosphates: $\mathrm{La}\left(\mathrm{PO}_{3}\right)_{3}$ and $\mathrm{LaP}_{5} \mathrm{O}_{14}$," Journal of Rare Earths, Vol. 28, No. 3, 2010, pp. 321-328. doi:10.1016/S1002-0721(09)60106-X

[3] S. Raynaud, E. Champion, D. Bernache-Assollant and P. Thomas, "Calcium Phosphate Apatites with Variable $\mathrm{Ca} / \mathrm{P}$ Atomic Ratio I. Synthesis, Characterization and Thermal Stability of Powders," Biomaterials, Vol. 23, No. 4, 2002, pp. 1065-1072. doi:10.1016/S0142-9612(01)00218-6

[4] B. Boonchom, C. Danvirutai and S. Maensiri, "Soft Solution Synthesis, Non-Isothermal Decomposition Kinetics and Characterization of Manganese Dihydrogen Phosphate Dihydrate $\mathrm{Mn}\left(\mathrm{H}_{2} \mathrm{PO}_{4}\right)_{2} \cdot 2 \mathrm{H}_{2} \mathrm{O}$ and Its Thermal Transformation Products," Materials Chemistry and Physics, Vol. 109, No. 2-3, 2008, pp. 404-410. doi:10.1016/j.matchemphys.2007.12.018

[5] S. V. Rathan, G. Govindaraj, "Thermal and Electrical Relaxation Studies in $\mathrm{Li}_{(4+x)} \mathrm{Ti}_{x} \mathrm{Nb}_{1-x} \mathrm{P}_{3} \mathrm{O}_{12}(0.0 \leq x \leq 1.0)$ Phosphate Glasses," Solid State Sciences, Vol. 12, No. 5, 2010, pp. 730-735.

[6] P. Shuetz and F. Caruso, "Electrostatically Assembled Fluorescent Thin Films of Rare-Earth-Doped Lanthanum Phosphate Nanoparticles," Chemistry of Materials, Vol. 14 , No. 11, 2002, pp. 4509-4516. doi: $10.1021 / \mathrm{cm} 0212257$

[7] F. Meiser, C. Cortez and F. Caruso, "Biofunctionalization of Fluorescent Rare-Earth-Doped Lanthanum Phosphate Colloidal Nanoparticles," Angewandte Chemie, Vol. 43, No. 44, 2004, pp. 5954-5957. doi:10.1002/anie.200460856

[8] H. Onoda, H. Nariai, A. Moriwaki, H. Maki and I. Motooka, "Formation and Catalytic Characterization of Various Rare Earth Phosphates," Journal of Materials Chemistry, Vol. 12, No. 6, 2002, pp. 1754-1760. doi: $10.1039 / \mathrm{b} 110121 \mathrm{~h}$

[9] H. Onoda, T. Ohta, J. Tamaki and K. Kojima, "Decomposition of Trifluoromethane over Nickel Pyrophosphate Catalysts Containing Metal Cation," Applied Catalysis A, Vol. 288, No. 1-2, 2005, pp. 98-103. doi:10.1016/j.apcata.2005.04.028

[10] H. Onoda, Y. Inagaki, A. Kuwabara, N. Kitamura, K. Amezawa, A. Nakahira and I. Tanaka, "Synthesis and Electric Conductivity of Bulk Tetra-Valent Cerium Pyrophosphate," Journal of Ceramic Processing Research, Vol. 11, No. 3, 2010, pp. 344-347.

[11] K. Rajesh, P. Shajesh, O. Seidei, P. Mukundan and K. G. K. Warrier, "A Facile Sol-Gel Strategy for the Synthesis of Rod-Shaped Nanocrystalline High-Surface-Area Lanthanum Phosphate Powders and Nanocoatings," Advanced Functional Materials, Vol. 17, No. 10, 2007, pp. 16821690. doi:10.1002/adfm.200600794

[12] H. Onoda, K. Taniguchi and I. Tanaka, "Additional Effects of Urea on Preparation and Acidic Properties of Lanthanum Orthophosphate," Microporous and Mesoporous Materials, Vol. 109, No. 1-3, 2008, pp. 193-198. doi:10.1016/j.micromeso.2007.04.043

[13] H. Onoda, H. Matsui and I. Tanaka, "Improvement of Acid and Base Resistance of Nickel Phosphate Pigment by the Addition of Lanthanum Cation," Materials Science and Engineering B, Vol. 141, No. 1-2, 2007, pp. 28-33. doi:10.1016/j.mseb.2007.05.009

[14] M. Bettinelli, F. Piccinelli, A. Speghini, J. Ueda and S. Tanabe, "Excited State Dynamics and Energy Transfer Rates in $\mathrm{Sr}_{3} \mathrm{~Tb}_{0.90} \mathrm{Eu}_{0.10}\left(\mathrm{PO}_{4}\right)_{3}$," Journal of Luminescence, Vol. 132, No. 1, 2012, pp. 27-29. doi:10.1016/j.jlumin.2011.07.018

[15] A. Tor, "Removal of Fluoride from Water Using Anion- 
Exchange Membrane under Donnan Dialysis Condition," Journal of Hazardrous Materials, Vol. 141, No. 3, 2007, pp. 814-818. doi:10.1016/j.jhazmat.2006.07.043

[16] C. M. Lew, Y. Liu, B. Day, G. M. Kloster, H. Tiznado, M. Sun, F. Zaera, J. Wang and Y. Yan, "Hydrofluoric-AcidResistant and Hydrophobic Pure-Silica-Zeolite MEL LowDielectric-Constant Films," Langmuir, Vol. 25, No. 9, 2009, pp. 5039-5044. doi:10.1021/la803956w

[17] D. E. C. Corbridge and E. J. Lowe, "The Infra-Red Spectra of Inorganic Phosphorus Compounds. Part II. Some
Salts of Phosphorus Oxy-Acids," Journal of the Chemical Society, Vol. 493, 1954, pp. 4555-4564.

doi:10.1039/jr9540004555

[18] E. Hemmer, K. Soga, T. Konishi, T. Watanabe, T. Taniguchi and S. Mathur, "Influence of the Host Phase on the Vibrational Spectra of Europium-Doped Zirconia Prepared by Hydrothermal Processing," Journal of the American Ceramic Society, Vol. 93, No. 11, 2010, pp. 38733879. doi:10.1111/j.1551-2916.2010.03981.x 